Jurnal Teknologi Informasi dan Komunikasi, ISSN: 2087-0868, Volume 9 Nomor 2, September 2018, Perancangan Web Desain Rencana Kegiatan dan Anggaran Sekolah (RKAS) Pada Sekolah Dasar

\title{
PERANCANGAN WEB DESAIN RENCANA KEGIATAN DAN ANGGARAN SEKOLAH (RKAS) PADA SEKOLAH DASAR
}

\author{
Ahmad Zainudin', Aan Tya Ervina ${ }^{2}$ \\ ${ }^{1,2}$ Program Studi S1:Desain Grafis, Sekolah Tinggi Elektronika dan Komputer, \\ Jl. Majapahit No 605, Kampus 1, Semarang, Indonesia 50275
}

\begin{abstract}
Abstrak
Pada SD Negeri 1 Rejosari Brangsong dalam pengelolaan keuangan yang terkait dengan RKAS masih menggunakan cara manual yaitu masih dicatat dalam buku dan menggunakan jurnal dan dalam penyusunan kegiatan dan anggaran sekolah masih menggunakan cara konvensional yaitu aplikasi Microsoft Excel. Sehingga petugas sering mengalami kesulitan dalam melakukan input data dan penghitungan total anggaran, seperti pencatatan pendapatan dan pengeluaran dana. Penyampaian laporan keuangan harian dari administrasi juga sering mengalami keterlambatan, mengingat kesibukan Kepala Sekolah yang sering tidak disekolah. Selain itu para orang tua atau wali murid juga kesulitan dalam memperoleh informasi keuangan sekolah dan mencari informasi terbaru mengenai sekolah dimana mayoritas orang tua dari siswa adalah pekerja.

SD Negeri 1 Rejosari Brangsong dituntut untuk dapat membuat pengelolaan yang terkait dengan RKAS menjadi lebih mudah dalam pencatatan maupun pelaporan.Sehingga dapat membuat SD Negeri 1 Rejosari Brangsong dapat bersaing dengan SD lain dalam pembuatan administrasi keuangan yang terkait dengan RKAS agar lebih rapi. Salah satu hal yang dapat ditempuh oleh SD Negeri 1 Rejosari Brangsong adalah dengan menggunakan Sistem Informasi Rencana Kegiatan dan Anggaran Sekolah (RKAS) SD Negeri 1 Rejosari Brangsong berbasis Web yang lebih efektif, efisien, dan praktis dalam pencatatan dan pembuatan pelaporan RKAS secara cepat dan data-data dapat terkomputerisasi sehingga lebih aman. Kemajuan teknologi dapat membantu bagian TU pada SD Negeri 1 Rejosari Brangsong dalam proses pencatatan dan pengelolaan serta pelaporan yang terkait dengan RKAS lebih mudah.
\end{abstract}

Kata kunci : Rejosari Brangsong, RKAS, konvensional, Web

\section{Pendahuluan}

Seiring dengan perkembangan zaman dan pesatnya kemajuan Teknologi Informasi dewasa ini, informasi merupakan hal yang sangat penting dalam menjalankan suatu pekerjaan dan kegiatan usaha. Teknologi Informasi merupakan sarana yang sangat penting dan menunjang bagi suatu badan/ instansi/ departemen/ perusahaan baik negeri maupun swasta dalam skala kecil, sedang, ataupun besar, sehingga dengan informasi dapat diharapkan mempermudah pekerjaan dan tujuan dapat tercapai secara maksimal dalam waktu yang efektif dan efisisen.

Rencana Kegiatan dan Anggaran Sekolah (RKAS) merupakan unsur pokok dalam kelangsungan hidup sekolah, dimana RKAS tersebut terdapat rencana-rencana pokok dan realisasi anggaran dalam mengelola sekolah. Pengembangan sekolah juga biasa dilihat dari pengelolaan anggaran yang bagus untuk memenuhi kebutuhan-kebutuhan harian, bulanan maupun tahunan sekolah.

SD Negeri 1 Rejosari Brangsong beralamat di J1. Laut Tengah Desa Rejosari, Kecamatan Brangsong, Kabupaten Kendal. Merupakan salah satu instansi pendidikan sekolah tingkat dasar. Salah satu contoh dari aktivitas yang ada didalam SD Negeri 1 Rejosari Brangsong adalah pengelolaan Rencana Kegiatan dan Anggaran Sekolah (RKAS) yang dibuat per satu tahun anggaran atau per satu tahun pelajaran, sebagai rincian Rencana Kegiatan dan Anggaran Sekolah (RKAS) yang akan dilakukan pada tahun pelajaran tersebut.

Adapun keuangan yang dikelola dari sumber pendapatan sampai pengeluaran antara lain: penerimaan dana BOS, penerimaan iuran tes semester, penerimaan iuran ekstrakurikuler, dan penerimaan iuran latihan ujian atau try out bagi kelas VI. Sedangkan pengeluaran yang dikelola dari RKAS tersebut meliputi : gaji atau honor, administrasi, tunjangan jabatan, pengadaan media pembelajaran, sampai kegiatan peningkatan 
Jurnal Teknologi Informasi dan Komunikasi, Volume 9 Nomor 2, September 2018

mutu sekolah. RKAS disusun disetujui oleh beberapa pihak yaitu, komite sekolah, wali murid dan pihak sekolah itu sendiri.

Pada SD Negeri 1 Rejosari Brangsong dalam pengelolaan keuangan yang terkait dengan RKAS masih menggunakan cara manual yaitu masih dicatat dalam buku dan menggunakan jurnal dan dalam penyusunan kegiatan dan anggaran sekolah masih menggunakan cara konvensional yaitu aplikasi Microsoft Excel. Sehingga petugas sering mengalami kesulitan dalam melakukan input data dan penghitungan total anggaran, seperti pencatatan pendapatan dan pengeluaran dana.

Penyampaian laporan keuangan harian dari administrasi juga sering mengalami keterlambatan, mengingat kesibukan Kepala Sekolah yang sering tidak disekolah. Selain itu para orang tua atau wali murid juga kesulitan dalam memperoleh informasi keuangan sekolah dan mencari informasi terbaru mengenai sekolah dimana mayoritas orang tua dari siswa adalah pekerja.

Tabel 1. Laporan Keuangan RKAS Tahun Anggaran 2011 s/d 2015

\begin{tabular}{|l|l|l|l|}
\hline No & Tahun Anggaran & Jumlah Anggaran & Jumlah Realisasi \\
\hline 1. & Tahun 2015 & Rp 109.600.000,00 & Rp 109.600.000,00 \\
\hline 2. & Tahun 2014 & Rp 98.360.000,00 & Rp 98.360.000,00 \\
\hline 3. & Tahun 2013 & Rp 96.615.000,00 & Rp 96.615.000,00 \\
\hline 4 & Tahun 2012 & Rp 109.780.000,00 & Rp 109.780.000,00 \\
\hline 5. & Tahun 2011 & Rp 102.400.000,00 & Rp 102.400.000,00 \\
\hline
\end{tabular}

Sumber : SD Negeri 1 Rejosari Brangsong

Melihat kelemahan-kelemahan yang ada pada sistem yang berjalan pada saat ini seperti yang sudah diuraikan di atas, untuk itu penulis bermaksud ingin memberikan solusi untuk mengatasi kelemahankelemahan pada sistem yang berjalan agar dapat membantu meningkatkan pekerjaan serta mengatasi permasalahan tersebut dengan merancang "Sistem Informasi Rencana Kegiatan dan Anggaran Sekolah (RKAS) SD Negeri 1 Rejosari Brangsong Berbasis Web".

Sesuai dengan perumusan masalah diatas, adapun tujuan dari penelitian ini adalah sebagai berikut :

Membantu sekolah dalam penyusunan dan pengelolaan RKAS selama satu tahun berbasis Web.

Membantu bagian administrasi dalam menunaikan tugas, yaitu membuat laporan anggaran sekolah berbasis Web.

Membantu pihak komite dan wali murid dalam memperoleh data anggaran dan informasi sekolah berbasis Web.

\section{Landasan Teori}

1. Web

Bekti (2015:35), Website merupakan kumpulan halaman - halaman yang digunakan untuk menampilkan informasi teks, gambar diam atau gerak, animasi, suara dan atau gabungan dari semuanya, baik yang bersifat statis maupun dinamis yang membentuk satu rangkaian bangunan yang saling terkait, yang masing - masing dihubungkan dengan jaringan - jaringan halaman.

Menurut Hanson Ward (2010:p4) Web adalah system hypermedia yang berarea luas yang ditunjukan untuk akses secara universal. Salah satu kuncinya adalah kemudahan tempat seseorang atau perusahaan dapat menjadi bagian dari web berkontribusi pada web. Web juga merupakan sistem yang menyebabkan pertukaran data di internet menjadi mudah dan efisien.

2. PHP

Menurut Bunafit Nugroho (2012:139) PHP adalah singkatan dari PHP Hypertext Preprocessor. PHP merupakan bahasa program yang berbentuk script yang diletakkan di dalam server web. PHP telah diciptakan terutama untuk kegunaan web dan dapat menghubungkan query database serta menggunakan perintah-perintah sederhana / simple task yang dapat diluruskan dalam 3 atau 4 baris kode saja. PHP adalah bahasa pemrograman yang baru di bangun sekitar tahun 1994 / 1995. PHP dapat menggantikan static website yang menggunakan HTML ke dynamic web pages yang berfungsi secara otomatis seperti ASP, CGI dan sebagainya.

Keuntungan menggunakan PHP adalah sebagai berikut:

a. PHP merupakan program open source (tidak memerlukan biaya lisensi).

b. Multi-platform (dapat dijalankan pada sistem operasi yang berbeda-beda).

c. Adanya penggunaan session / sesi.

3. MySQL 
Jurnal Teknologi Informasi dan Komunikasi, ISSN: 2087-0868, Volume 9 Nomor 2, September 2018, Perancangan Web Desain Rencana Kegiatan dan Anggaran Sekolah (RKAS) Pada Sekolah Dasar

Madcoms (2016:17), MySQL adalah sistem manajemen database $S Q L$ yang bersifat Open Source dan paling populer saat ini. Sistem database MySQL mendukung beberapa fitur seperti multithreaded, multi-user, dan SQL database manajemen system (DBMS). Bunafit Nugroho (2012:p29) mengemukakan, MySQL (My Structure Query Language) adalah sebuah program pembuat database yang bersifat open source, artinya siapa saja dapat menggunakanya secara bebas. MySQL sebenarnya produk yang berjalan pada platform Linux. Karena sifatnya yang open source, MySQL dapat berjalan pada semua platform baik Windows maupun linux. Selain itu, MySQL juga merupakan program pengakses database yang bersifat jaringan sehingga dapat digunakan untuk aplikasi multi-user (banyak pengguna). Saat ini database MySQL telah digunakan hampir oleh semua pemrogram database, terlebih dalam pemrograman web.

4. Adobe Dreamweaver CS 6

Dreamweaver merupakan suatu perangkat lunak web editor keluaran Adobe system yang digunakan untuk membangun dan mendesain suatu website dengan fitur-fitur yang menarik dalam penggunaanya (Muhammad Sadeli, 2014:6).

Untuk memahami ruang kerja Dreamweaver, bukalah sebuah file HTML baru dalam dreamweaver. Setelah dreamweaver berhasil dijalankan, pilih file baru (Create new) tipe HTML dalam kotak dialog New document yang tampil. Ruang kerja dasar dreamweaver adalah sebagai berikut:

a. Properties Bar, adalah sekumpulan menu yang digunakan untuk menampilkan menu-menu toolbar yang akan digunakan sesuai dengan kebutuhan serta mangatur tampilan dokumen dan fungsi lainya.

b. Document Toolbar, adalah lembar yang digunakan untuk menampilkan file-file dokumen yang anda buat berupa jendela dokumen (berbentuk tab). Document Toolbar mempunya tiga tab yang dapat membantu anda untuk mendesain web seperti Code, Split, dan Design.

c. Document Windows, adalah jendela document yang digunakan untuk meletakan objek-objek atau komponen untuk membuat dan merancang website.

d. Properties Inspector, adalah properties tab yang digunakan untuk mengatur properties dari objek-objek yang digunakan seperti mengatur jenis font, warna, ukuran teks dan lain sebagainya.

e. Panel Groups, adalah kumpulan panel-panel pelengkap yang berfungsi untuk mengorganisir, mengatur serta pelengkap website yang akan dibuat, contohnya panel CSS, berfungsi mempercantik tampilan website yang dibuat. Pada Dreanweaver CS 6 ini terdapat beberapa panel baru salah satunya seperti Browser Labs.

\section{Metodologi}

Model penelitian yang digunakan oleh penulis dengan menggunakan model pengembangan Research and Development (RnD) Soegiyono (2008:407), berpendapat bahwa metode penelitian dan pengembangan metode penelitian yang digunakan untuk menghasilkan produk tertentu dan menguji keaktifan produk tersebut. Untuk menghasilkan produk tertentu dugunakan penelitian yang bersifat analisis kebutuhan (digunakan metode survey atau kualitatif) dan untuk menguji keefektifan produk tersebut supaya dapat berfungsi di masyarakat luas, maka diperlukan penelitian untuk menguji keefektifan produk tersebut (digunakan metode eksperimen).

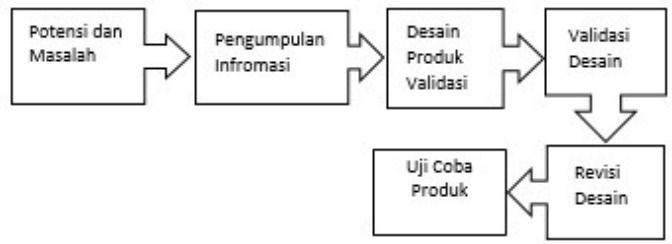

Gambar 1 Prosedur pengembangan metode R\&D

Untuk dapat memahami tiap langkah tersebut dapat dijelaskan sebagai berikut:

a. Potensi dan Masalah

Penelitian selalu bermula dari adanya potensi atau masalah. Potensi merupakan segala sesuatu yang jika didayaguakan akan mempunyai nilai tambah. Masalah juga dapat diubah menjadi sebagai potensi, apabila peneliti bisa mendayagunakan masalah tersebut. Masalah akan terjadi bila ada penyimpanan, antara yang diharapkan dengan keadaan yang terjadi. Masalah ini bisa diatasi melalui R \& D yaitu dengan cara menelitinya, sehingga bisa ditemukan suatu model, sistem atau pola pengembangan terpadu yang efektif yang bisa dipakai untuk mengatasi masalah tersebut.

b. Pengumpulan Data dan Informasi 
Jurnal Teknologi Informasi dan Komunikasi, Volume 9 Nomor 2, September 2018

Sesudah pontensi dan masalah bisa ditunjukkan secara faktual dan up to date, langkah berikutnya adalah mengumpulkan berbagai informasi dan studi literatur yang bisa dipakai sebagai bahan guna merencanakan pembuatan produk tertentu yang diharapkan bisa mengatasi masalah tersebut. Studi ini ditunjukan guna menemukan konsep - konsep maupun landasan - landasan teoritis yang bisa memperkuat suatu produk, misalnya produk yang berbentuk program, model, sistem, software, pendekatan, dan sebagainya.

\subsection{Bahan Penelitian}

Untuk menjalankan sistem berbasis web ini minimal harus memenuhi spesifikasi sebagai berikut :

a. Software

b. Hardware

Sistem operasi $\quad$ : Microsoft Windows 7/8/10

$\begin{array}{ll}\text { Processor } & : \text { Dual Core } \\ \text { RAM } & : 2 \mathrm{~Gb} \\ \text { Monitor } & : \text { SVGA dengan resolusi } 800 \text { x } 600 \text { dengan } 16 \text { bit } \\ & \text { color } \\ \text { Memori VGA } & : 1 \mathrm{Mb} \\ \text { Sound card } & : \text { diperlukan } \\ \text { CD drive } & : \text { tidak diperlukan jika mahasiswa mengakses } \\ & \text { melalui jaringan } \\ \text { Media output audio : } & \text { speaker atau earphone }\end{array}$

4. Hasil dan Pembahasan

1. Halaman Beranda SD Rejosari

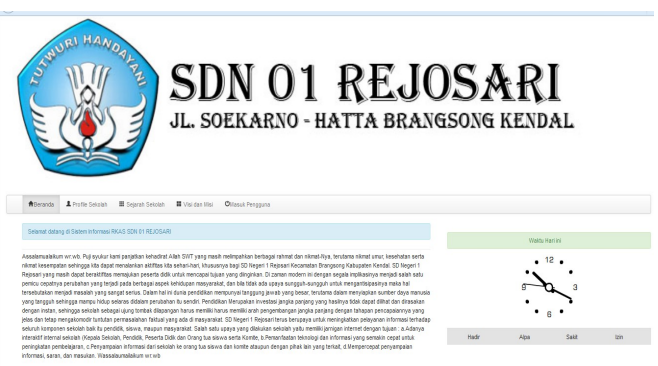

Gambar 1. Tampilan Beranda

Halaman beranda berisi tentang selayang pandang dari Kepala Sekolah dan penjelasan tentang tujuan dibuatnya Sistem Informasi Rencana Kegiatan dan Anggaran Sekolah (RKAS) Berbasis $W e b$

2. Halaman Sejarah Sekolah

Halaman sejarah sekolah adalah halaman untuk melihat sejarah berdirinya SD Negeri 1 Rejsari

Brangsong

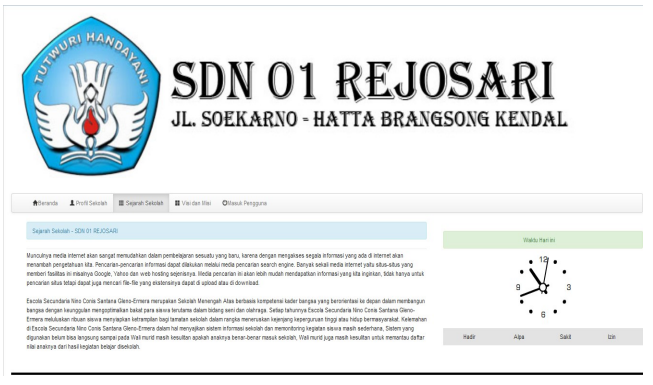

Gambar 2. Tampilan Sejarah Sekolah

3. Halaman Visi - Misi 
Jurnal Teknologi Informasi dan Komunikasi, ISSN: 2087-0868, Volume 9 Nomor 2, September 2018, Perancangan Web Desain Rencana Kegiatan dan Anggaran Sekolah (RKAS) Pada Sekolah Dasar

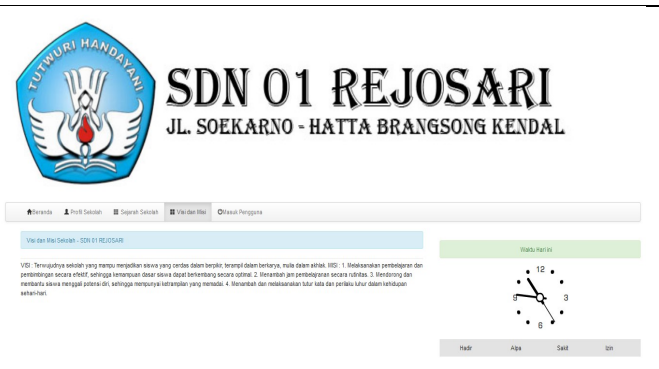

Gambar 3. Tampilan Visi - Misi

4. Halaman Login

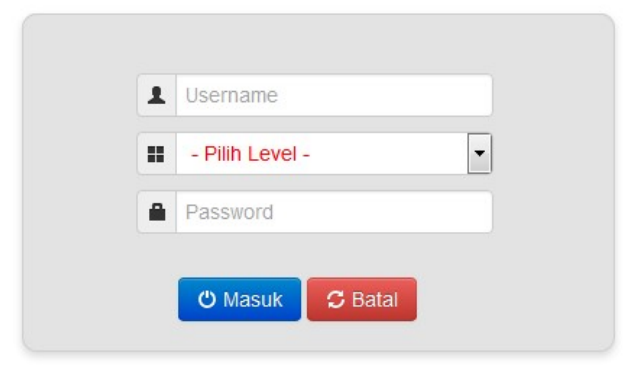

Gambar 4. Tampilan Login

Halaman masuk pengguna adalah halaman yang digunakan untuk login admin, TU, Kepala Sekolah, dan Komite dengan cara memasukkan username, pilih level, dan password sesuai dengan pengguna yang akan login.

5. Halaman Pengguna Admin

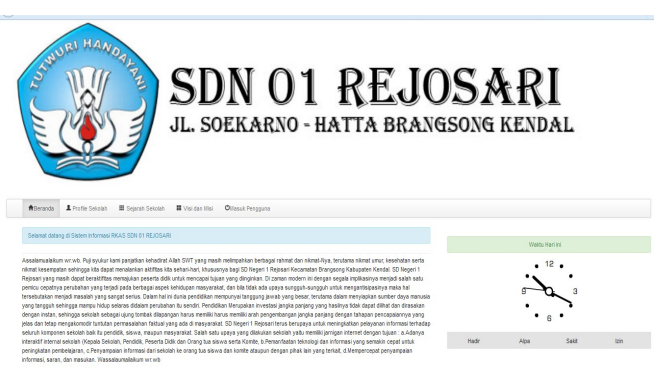

Gambar 5. Tampilan Pengguna Admin

\section{Kesimpulan}

Dari penjelasan yang telah diuraikan pada bab - bab sebelumnya, maka dapat ditarik kesimpulan sebagai berikut :

a) Sistem Informasi Rencana Kegiatan dan Anggaran Sekolah (RKAS) SD Negeri 1 Rejosari Brangsong Berbasis Web dapat berjalan secara efektif di dalam pengelolaan RKAS.

b) Adanya kemudahan dalam penyusunan kegiatan dan anggaran sekolah karena sistem berbasiskan Web yang bisa di akses kapan saja dan dimana saja. 
c) Adanya kemudahan dalam penyusunan laporan keuangan bulanan dan tahunan kepada pihak komite.

d) Membuat pengguna terutama Bendahara Bagian TU SD Negeri 1 Rejosari Bangsong menjadi terbantu dalam mengakses informasi-informasi dan kemudahan dalam berbagi pengetahuan proses pengelolaan Rencana Kegiatan dan Anggaran Sekolah (RKAS).

\section{Daftar Pustaka}

Anhar, 2010, "Panduan Menguasai PHP \& MySQL Secara Otodidak”, Jakarta : Mediakita

Anggraini, Ristya Dwi, 2013, “Transparansi, Partisipasi, dan Akuntabilitas Pengelolaan Anggaran Dana BOS Dalam RKAS di SDN Pacarkeling VIII Surabaya”, Surabaya : Universitas Airlangga.

Arief, M. Rudyanto, 2011, "Pemrograman Web Dinamis menggunakan PHP MySQL", Yogyakarta : Andi.

Kurniady, Dedy Achmad, 2011, "Pengelolaan Pembiayaan Sekolah Dasar di Kabupaten Bandung", Bandung : Universitas Pendidikan Indonesia.

Permendiknas Nomor 19, 2007, "Petunjuk Teknis Penggunaan dan Pertanggung jawaban Keuangan Dana Bantuan Operasional Sekolah Tahun Anggaran 2015", Jawa Tengah : Kementrian Pendidikan dan Kebudayaan.

Fitri, Afriliana, 2014, "Pengelolaan Dana Bantuan Operasional Sekolah (BOS) Sekolah Dasar Negeri Kecamatan Mandiangin Koto Selayan Kota Bukittinggi”, Bukittinggi : Administrasi Pendidikan FIP UNP.

Sugiono, 2010, “Metode Penelitian Kuantitatif Kualitatif dan R\&D”, Bandung : Alpabeta.

Simarmata, Janner, 2010, “Rekayasa Web”, Yogyakarta : Andi.

Sutabri, Tata, 2012, “Analisis Sistem Informasi”, Yogyakarta : Andi.

Sutanta, Edhi, 2011, “Basis Data dalam Tinjauan konseptual”, Yogyakarta : Andi.

Yakub, 2012; "Pengantar Sistem Informasi”, Yogyakarta : Graha Ilmu 